\title{
A legislação antirracista e a escola como lugar de confissão
}

\author{
The antiracist legislation and school as place of confession
}

\author{
Dirce Eleonora Nigro Solis*, Fábio Borges do Rosario**
}

Resumo: Neste trabalho investigamos como a desconstrução tal como formulada pelo filósofo da différance Jacques Derrida contribui no apelo pela desconstrução da escola básica. Consideramos como a legislação antirracista aponta para a superação da hostilidade racista. Verificamos como a escola poderia ser o local de confissão dos crimes cometidos contra a humanidade e em qual medida tal profissão apela e deputa um horizonte aonde chega à hospitalidade in-condicional.

Palavras-chaves: Legislação antirracista; Confissão; Escravidão; Escola.

Abstract: In this work we investigate how the deconstruction, as formulated by the philosopher of différance Jacques Derrida, contributes in the appeal for the deconstruction of the basic school. We consider how anti-racist legislation points to overcoming racist hostility. We verified how the school could be the place of confession of the crimes committed against humanity and to what extent this profession appeals and deputates a horizon where it arrives at the in--conditional hospitality.

Keywords: Anti-racism legislation, Confession, Slavery, School.

\section{Travessias}

Com e a partir de Jacques Derrida $^{1}$ investigamos se a legislação antirracista ${ }^{2}$ brasileira pode ser entendida como um ato jurídico-performático que apela o acontecimento de confissão do cometimento de crimes contra a humanidade pelos lusitanos e pelos luso-descendentes, isto é, a confissão da Escravidão. Analisamos se a escola e a universidade são conclamadas pela legislação a apresentarem-se como o lugar da

\footnotetext{
" Doutora em Filosofia pela Universidade do Estado do Rio de Janeiro - UERJ. Professora titular de Filosofia na Universidade do Estado do Rio de Janeiro - UERJ. Coordenadora do Laboratório de Licenciatura e Pesquisa sobre o Ensino de Filosofia - UERJ. E-mail: dssolis@gmail.com

${ }^{* *}$ Mestre em Filosofia e Ensino pelo Centro de Educação Tecnológica Celso Suckow da Fonseca - CEFET/RJ. Professor de filosofia na Seeduc-RJ. E-mail: professorfilosofiafabio@gmail.com

${ }^{1}$ DERRIDA, Du droit à la philosophie, 1990 ; DERRIDA, Margens da filosofia, 1991; DERRIDA, A farmácia de Platão, 1991b; DERRIDA, O outro cabo, 1995; DERRIDA, Une Europe de l' espoir, 2004b; DERRIDA, Força de lei: o fundamento místico da autoridade, 2007; DERRIDA, Adeus a Emmanuel Lévinas, 2008; DERRIDA, Gramatologia, 2011b.

${ }^{2}$ BRASIL, Diretrizes curriculares nacionais para educação das relações étnico-raciais e para o ensino de história e cultura afro-brasileira e africana, 2005; BRASIL, Orientações e ações para educação das relações étnico-raciais, 2006; BRASIL, Lei no 11.645 de 10 de março de 2008, 2008
} 
pesquisa e investigação, e da formação dos profissionais que publicarão, confessarão, declararão, arrepender-se-ão, expiarão e solicitarão perdão pelos crimes cometidos contra a humanidade, tais como, a Escravidão.

O filósofo conflui em si a herança do judeu exilado pelo governo lusitano, marrano exilado na Argélia, judeu de cidadania francesa, judeu sem cidadania, cidadão francoargelino radicado na França. Sua recusa por optar por uma das heranças, a experimentação de vivenciar as agruras do desenraizado, talvez, aponte uma rota na direção da superação do binarismo étnico que marca a sociedade colonizada tanto na Europa quanto nos outros continentes. A crise ontológica europeia, a busca pela eliminação das diferenças étnicas, a hostilização da herança considerada estrangeira, a hierarquização das etnias e a desumanização das consideradas inferiores foi exportada pelos europeus para os territórios invadidos e transformados em colônias.

Pedimos inicialmente licença aos que chegaram primeiro nesta avenida aberta por Jacques Derrida. E em nome da fidelidade infiel, ousa-se aqui diante dos ausentes e dos presentes, reivindicar o legado para ir a outras margens e contra-assinar com e em nome daqueles espectros que foram hostilizados, mas que retornam para acolher e apelar travessias descolonizadas e desconstruídas entre a América, África, Europa, Ásia e Oceania.

Anima à pesquisa a via aberta por Dirce Solis quando ${ }^{3}$ conclama os filósofos a investigarem quais espectros assombram a Filosofia ou quando ${ }^{4}$ põe na cena e no encontro entre Filosofia e Arquitetura o espectral Complexo Penal da Ilha Grande ou quando ${ }^{5}$ estima que a desconstrução fará diferença, se após perceber a in-decidibilidade, assumir a responsabilidade e decidir pela construção de um mundo digno para as singularidades humanas. Por Marcelo Moraes e Adriano Negris ${ }^{6}$ que apelam a acolhida do outro quando apresentam como a desconstrução abala a ética ou quando trazem a discussão da transgressão, do vadio e narram a história de Madame Satã; via que Marcelo ${ }^{7}$ percorre transgredindo, suleando, afrocentrando a filosofia, contra-assinando a obra derridiana ao atravessá-la com as filosofias africanas e ameríndias. E, por Rafael Hadock Lobo quando ${ }^{8}$

\footnotetext{
${ }^{3}$ LOBO, Heranças de Derrida: da ética a política, 2014.

${ }^{4}$ SOLIS; MORAES, Políticas do lugar, p. 18-53.

${ }^{5}$ SOLIS, Desconstrução em arquitetura e hospitalidade: uma abordagem a partir de Derrida, 2004; SOLIS, Jacques Derrida e a ética da hospitalidade, 2005; SOLIS, Desconstrução e arquitetura: uma abordagem a partir de Jacques Derrida, 2009; SOLIS, Retórica e desconstrução segundo Jacques Derrida, 2012.

${ }^{6}$ SOLIS; MORAES, Políticas do lugar, p. 54-85; MORAES; SANTOS, O pensamento do ético em Jacques Derrida: uma questão de hospitalidade, 2017.

${ }^{7}$ MORAES, Desobediência epistemológica: Ubuntu e Teko porã: outros possíveis a partir da desconstrução, 2017; MORAES, Desconstruindo o epistemicídio a partir de Jacques Derrida, 2017b; MORAES, Democracias espectrais: uma abordagem a partir de Jacques Derrida, 2018.

${ }^{8}$ LOBO; PEREIRA, Por uma topografia das assombrações: os espectros da desconstrução para-além e para-aquém do Mediterrâneo e do Atlântico [No prelo].
} 
acolhe a proposta derridiana de buscar noutras mitologias os temas de pesquisa e desce ao Sul, cruza o Mediterrâneo e o Saara para encontrar com Babá Egun - espectro e ancestral , e com toda a ancestralidade preta e branca navega pelo Atlântico rumo às terras americanas dos rastros e heranças da Umbanda. Estes captaram a voz derridiana na "Palavra Soprada" , onde aponta a busca por horizontes para além da tradição europeia, ao dizer que: "fora da Europa, no teatro balinês, nas velhas cosmogonias mexicana, hindu, iraniana, egípcia, etc., procurar-se-á sem dúvida temas, mas também, por vezes modelos de escritura”.

\section{A desconstrução e a legislação antirracista}

Descrevemos que a legislação antirracista brasileira ${ }^{10}$ pode ser entendida como um ato jurídico-performático na medida em que escutamos a obra $A$ universidade sem condição ${ }^{11}$. Entendemos, aqui, a legislação antirracista como resultado da resistência, dissidência ou "como uma espécie de princípio de desobediência civil"12 dos negros brasileiros que permite, "pelo direito e pela filosofia, pela crítica, pelo questionamento, pela desconstrução" ${ }^{13}$ repensar a história do país. Ou seja, como um ato jurídicoperformático que possibilita ultrapassar o Direito e "faz operar ou inspira a desconstrução como justiça” ${ }^{14}$.

Acatamos que, tanto no período imperial quanto no republicano, os intelectuais e legisladores brasileiros buscavam inspirar-se nas ideias em voga no continente europeu. Esta contaminação pelo ideário e filosofema europeu os separava entre os que defendiam a abolição imediata e os que defendiam a abolição progressiva da escravatura; entre os que defendiam legislações que fundassem a segregação pigmentar entre brancos e negros e os que defendiam o silenciamento legislativo quanto aos negros, isto é, abandoná-los à própria sorte, o que implicaria o insucesso coletivo destes. Tais ideias, independente da radicalidade com que eram defendidas ou do abismo teórico e prático entre seus defensores, refletem que o eurocentrismo estava no horizonte previsto pelos intelectuais e legisladores para a nação.

Noutro sentido, o de abandonar a hostilidade e promover a hospitalidade é que propomos entender a legislação antirracista brasileira como um ato jurídico-performático de confissão do crime contra a humanidade, a Escravidão, cometido pelos portugueses e

\footnotetext{
${ }^{9}$ DERRIDA, A escritura e a diferença, p. 283.

${ }^{10}$ Ver também ROSÁRIO, A desconstrução do ensino de filosofia e a legislação antirracista, 2013. ROSÁRIO, A desconstrução do ensino de filosofia e o movimento das mulheres negras, 2018.

${ }^{11}$ DERRIDA, A universidade sem condição, 2003.

${ }^{12}$ Ibidem, p. 24.

${ }^{13}$ Ibidem, p. 23.

${ }^{14}$ Ibidem, p. 24.
} 
seus descendentes e sofrido pelos povos que habitavam o atual território brasileiro antes da chegada dos lusitanos e contra as etnias capturadas e escravizadas no continente africano e deportadas para o Brasil.

Para alcançar a finalidade proposta, pela legislação antirracista, o signatário (legisladores do Congresso Nacional que aprovaram e os presidentes da República que sancionaram as legislações ou os conselheiros do Conselho Nacional de Educação ou Ministros da República que aprovaram as Resoluções, Diretrizes, Orientações e Planos) resolve que os destinatários implementarão as ações previstas. Sendo destinatários: os gestores e docentes das instituições superiores, os gestores dos sistemas estaduais e municipais, professores, coordenadores pedagógicos etc.

O signatário resolve que os destinatários reconheçam, identifiquem e valorizem as diferentes vozes que marcam a história e a sociedade brasileira mediante a reformulação do conteúdo dos currículos que passarão a observar conforme o $\operatorname{Art} 2^{\circ} \S 2^{\circ}$ :

O Ensino de História e Cultura Afro-brasileira e Africana tem por objetivo o reconhecimento e valorização da identidade, história e cultura dos afrobrasileiros, bem como a garantia de reconhecimento e igualdade de valorização das raízes africanas da nação brasileira, ao lado das indígenas, europeias, asiáticas ${ }^{15}$.

Resolve ainda os signatários que os destinatários devem notificar os gestores do sistema educacional a fim de garantir o cumprimento dos dispositivos legais e evitar que o performativo-jurídico entre no rol das leis que não são observadas e cumpridas no cotidiano.

E lembramos que a legislação antirracista brasileira, para além da vontade dos signatários insere-se num movimento internacional que conforme, Derrida:

Bem próxima da profissão de fé, essa alusão à confissão poderia encadear meu discurso à análise do que acontece hoje, na cena mundial, semelhante a um processo universal de confissão, de declaração, de arrependimento, de expiação e de perdão solicitado. Poder-se-iam citar mil exemplos, dia após dia. Porém, quer sejam crimes muito antigos ou crimes de ontem, a escravidão, a Shoah, o apartheid ou as violências da Inquisição (sobre a qual o Papa há pouco anunciou que deveria dar lugar a um exame de consciência), o arrependimento vem sempre, explícita ou implicitamente, com referência a esse conceito jurídico bastante jovem de "crime contra a humanidade" ${ }^{16}$.

\footnotetext{
${ }^{15}$ BRASIL, Diretrizes curriculares nacionais para educação das relações étnico-raciais e para o ensino de história e cultura afro-brasileira e africana, p. 31.

${ }^{16}$ DERRIDA, A universidade sem condição, p. 19.
} 
Quando dizemos, aqui, que a legislação é um ato jurídico-performático para a população negra, tomamos o termo performativo no sentido do quase-conceito derridiano de performativo. O performativo, diz Jacques Derrida ${ }^{17}$, produz o acontecimento que enuncia, e os performativo-jurídicos são aqueles que, desde as primeiras declarações de direitos até as mais recentes, implicam uma promessa, prometem desde os direitos fundamentais a homens e mulheres até a confissão dos crimes cometidos contra a humanidade, tais como a Escravidão, a Shoah e o Apartheid. Quando o filósofo advoga que o performativo produz o acontecimento que enuncia, pretende demonstrar que entende por acontecimento o que chega de fora, para além de todo performativo enunciado, além do horizonte de possibilidades.

A força do performativo é excedida pela força do acontecimento, pois esta se torna manifesta quando o que acontece solicita a decisão, a decisão do outro, a chegada do outrem. A força do acontecimento, deste talvez, afina-se com o operatório performativo, com a gramática do condicional para declarar o incondicional, o totalmente outro, extremamente difícil, quase improvável, quase indemonstrável na trajetória de submeter à soberania atribuída às instituições e mostrar certa independência incondicional do pensamento, da desconstrução, da justiça, etc. E quanto aos signatários de um performativo-jurídico, afirma que são, ao mesmo tempo, signatários e destinatários, pois o acontecimento que foi enunciado tem consequências inimagináveis.

\section{A legislação antirracista como acontecimento}

Apontamos que a legislação antirracista brasileira ${ }^{18}$ pode ser entendida como um acontecimento do pensamento ao passo que ouvimos do filósofo marrano ${ }^{19}$ que a desconstrução não é nem um método, nem uma doutrina, nem uma metafilosofia especulativa; quando professa a desconstrução como um acontecimento. E por acontecimento, entende um talvez que se afina com a impossibilidade; cuja força, a força do que acontece, comporta para o agente, no momento da decisão, certa passividade diante da decisão do outro que chega. O acontecimento, portanto, não é um mero performativo, uma ação autorizada convencionalmente ou fundada numa comunidade institucional que valida os atos de um agente diante do alter. O acontecimento é da ordem do por-vir, pertence ao horizonte do im-possível, pois:

Desde o princípio, foi dito com clareza que a desconstrução não é um processo ou um projeto marcado pela negatividade, nem mesmo essencialmente pela "crítica" (valor que tem uma história, como a da

\footnotetext{
17 Ibidem.

${ }^{18}$ Ver também ROSÁRIO, O conceito de antirracismo e a confissão de crimes contra a humanidade, $2017 \mathrm{~b}$.

${ }^{19}$ Ibidem.
} 
"questão", história esta que provavelmente convém manter viva, mas que tem seus limites). A desconstrução é antes de tudo a reafirmação de um sim originário. Afirmativo não quer dizer positivo. Esclareço de maneira esquemática esse ponto, pois para alguns, como a afirmação se reduziria após uma fase de demolição. Não há demolição tanto quanto reconstrução positiva e não "há fase" 20 .

Traçamos que a legislação é um acontecimento no sentido que aponta como horizonte - ao mesmo tempo a abertura e o limite da abertura, define ou um progresso infinito, ou uma espera - confessar a Escravidão, a Shoah e o Apartheid como crimes contra a humanidade, o que possibilita desviar da espectralidade da raça como hostilidade e pensar a raça como rastro, como espectro que não mais assombra, e, sim, desvia, reconhece e encontra na hospitalidade in-condicional caminhos para a superação dos efeitos que tais eventos produziram. E compreender a im-possibilidade como condição de possibilidade na procura por caminhos que desviem da situação atual de dominação onde o traço racial como motor do ódio se impõe disfarçadamente.

E a tomamos como restância da Abolição que chegou como evento e como acontecimento. Como evento para aqueles que a consideraram um fato histórico decorrente da conjuntura internacional e nacional, que se adequaram à nova situação econômica do país e preferiram silenciar o passado escravista do país que consideraram inadequado com os novos tempos; e como Acontecimento para os negros que, agora libertos, teriam que lutar pela sobrevivência e inserção na vida da nação, e para os intelectuais e políticos que entendiam que a Abolição não fora um mero evento, mas que prenunciava novos apelos de inserção do negro no novo sistema econômico do país e, principalmente, que o tratamento a ser dispensado aos afro-luso-brasileiros e aos negros seria crucial na definição e constituição da identidade nacional brasileira.

\section{A escravidão: silenciamento e memória}

Reconhecemos que a legislação antirracista brasileira rompe com o silenciamento e deputa à confissão da Escravidão como um crime cometido pelos lusitanos e seus descendentes contra as etnias que habitavam o continente americano e contra as etnias deportadas sob cativeiro do continente africano. Escutamos ainda a advertência, da Lettre à un ami japonais ${ }^{21}$, que a desconstrução é um acontecimento; aquilo que chega, o que inspira a investigar como o acontecimento da Abolição da escravidão, repercutiu no cotidiano.

E para entender como a memória da Escravidão será relatada e experienciada pelas novas gerações auscultamos da obra “O perdão, a verdade, a reconciliação: qual gênero?” 22 ,

\footnotetext{
${ }^{20}$ DERRIDA, Posições, p. 350.

${ }^{21}$ DERRIDA, Psyché: Inventions de l'Autre. Paris: Galilée, 1987.

${ }^{22}$ NASCIMENTO, Jacques Derrida: pensar a desconstrução, p. 45-92.
} 
na qual o filósofo africano desenraizado apela à confissão do crime cometido contra os negros: o sequestro de sua liberdade via escravização, segregação, colonização, etc. Na qual refuta as teses que fundamentaram retirar o negro da história mundial, denuncia a situação atual de manutenção da exclusão sob as formas modernas do gueto, das favelas, dos presídios, etc., e conclama que a promessa feita nas declarações dos direitos humanos impossibilite qualquer possibilidade de retorno do racismo.

Entendemos, portanto, haver pistas que possibilitam recusar a ideologia da democracia racial como um mito e demonstrar que a nacionalidade brasileira fora forjada na desigualdade pigmentar entre brancos e negros. A desigualdade está fundada na crença branco-europeia da inferioridade dos negros e tal mentalidade e comportamento persistem até a contemporaneidade. Por isso, vários autores confirmam que, no caso brasileiro, não se verifica uma democracia racial, antes uma flagrante desigualdade pigmentar.

E talvez esta ignóbil desigualdade pigmentar seja a restância da Escravidão, a incapacidade de superar um filosofema que definiu o negro como essencialmente escravo. Jacques Derrida ${ }^{23}$, para denunciar, explicitar e desconstruir esta noção volta-se para o Hegel da Filosofia da história. Cujas afirmações sobre a África são consideradas inseparáveis do conjunto de sua conclamada obra. Hegel, diz, situa o continente africano na infância da humanidade, sem consciência, sem história, fora do palco da consciência como história e, como a cor negra de seus habitantes, prisioneiro da escuridão. Ao negar aos africanos as categorias da universalidade e da generalidade, o respeito a Deus e a lei, limita o conhecimento dos africanos apenas ao trovão de Deus e à magia, e ainda que reconheça que os negros têm ideia da existência da vida após a morte, nega-lhes a noção de imortalidade da alma, e em consequência nega-lhes o acesso ao direito. A negação do acesso ao direito insere-se no escopo de sua tese: a escravidão é o traço essencial do negro, este traço decorre de sua ainda não-consciência da liberdade; o "ainda não" marca seu atraso, sua letargia em passar da inconsciência para a consciência, e em consequência de sua não-passagem e por não serem livres, caem na categoria de coisa sem valor humano, mas que, transformados em mercadoria pelos humanos [entenda-se aqui, pelos brancos europeus], são reduzidos a escravidão e comercializados na América.

O abandono deste paradigma eurocentrado que inferioriza o negro-brasileiro é enunciado pelo performativo-jurídico brasileiro? Talvez, no revisitar a história na busca de traços da participação de todas as etnias que habitavam o país antes do aportamento lusitano e de todas as etnias deportadas ou que para cá emigraram se encontre os rastros que possibilitem uma nova memória nacional.

A legislação antirracista como um acontecimento do pensamento, prenuncia que se pense a paradoxal relação ente a memória e o esquecimento, questão que para a desconstrução remete para o por-vir, que o esquecimento ao mesmo tempo em que remete

${ }^{23}$ Ibidem. 
ao passado prenuncia o por-vir. Que quando se promete não se enuncia apenas um performativo cuja possibilidade de cumprimento é possível, quando se promete opera-se um engajamento que exige a responsabilidade com o cumprimento do prometido. $\mathrm{O}$ acontecimento chega como um monstro, cujo rastro remete para traços conhecidos ao mesmo tempo em que aponta para traços por-vir. Elenca o direito das vítimas ao riso, ao canto e as lágrimas; assinala que a situação da vítima é inesquecível, marginalizável e ilegível ao outro.

No momento da vitimização pretendia o algoz excluir o vitimado da linguagem e da história e do direito ao protesto ou ao riso ou ao canto ou às lágrimas, isto é, pretendia o apagamento da singularidade. Nesta direção operou o algoz o apagamento das provas e dos restos mortais, pretendendo a destruição da memória, o riscamento do nome da vítima e destruição da singularidade da vítima, buscou só deixar cinzas. E a cinza, enquanto traço do desaparecimento é também o rastro do que não se pode mais identificar, a incineração do corpo que conservaria a memória. Na cinza nada resta? As cinzas guardam o segredo do desaparecimento, conservam a memória do aniquilamento, e se não permitem a identificação do aniquilado, testemunham que algo ou alguém foi aniquilado. As cinzas são o rastro, tanto do aniquilado quanto do aniquilamento ${ }^{24}$.

Reafirmamos a partir das noções de esquecimento e memória a im-possibilidade da confissão deste crime pelos luso-descendentes. Alertamos que a confissão dos crimes pelos descendentes não se destina as vítimas. Confessar os crimes cometidos pelos ancestrais é comprometer-se e professar que não se cometerá os mesmos erros, enunciar a responsabilidade pela não repetição e decidir pela abertura a alteridade e engajar-se na busca pelos rastros que seus ancestrais pretendiam apagar.

Desviamos da noção do esquecimento como possibilidade de harmonia social. Formulamos que o silenciamento da memória obsidia o Estado brasileiro. E avaliamos que as narrativas da Escravidão permitem a todas as singularidades - independentemente do pertencimento étnico ou pigmentar - apelar pelo fim das desigualdades etnopigmentares.

E se conjurar o termo raça com a intenção de repelir o racismo, é a expectativa daqueles que algures acusam a legislação antirracista de conjurar, isto é, convocar, chamar de volta o espectro que assombra. Nesta escritura, entretanto, conjura-se, invoca-se, suplica-se o espectro da raça como recurso paleonímico e por economia para operar um desvio do sentido que o ideário racialista brasileiro imprimiu a raça, em especial a raça negra. E apontar que o espectro da raça, este retornante, retorna como confissão do crime cometido e profissão de que neste país não se cometerá novamente o crime da Escravidão.

\section{Brasil: do silenciamento a solidariedade}

\footnotetext{
${ }^{24}$ Ibidem.
} 
Se, identificamos no rastro da legislação o apelo pela confissão do silenciamento dos brasileiros diante da Escravidão é provavelmente porque muitos brasileiros ainda resistem ao apelo de confessarem que cometeram um crime contra a humanidade, a Escravidão. Escravidão que marcou a história e as relações entre negros e brancos no país, no passado colonial e republicano, ontem e hoje, nas senzalas e nas favelas, nos troncos e nas prisões, na escravização e no desemprego, o erro nacional originário de negar a liberdade.

Esta dificuldade em confessar o crime cometido, na esteira da leitura derridiana, contém-se numa tradição europeia, como se lê em Hegel, que considera que a Escravidão lançou os negros na história via sua cristianização e que somente mediante esta é que o negro é autorizado a entrar no teatro da história. Tal pensamento não enxerga os malefícios da escravidão, antes vê nesta um processo de humanização dos negros; nesta perspectiva é que Hegel defendia a abolição gradual da escravidão. Em sua concepção, após o processo escravidão-cristianização, os negros estariam prontos para participar da história ocidental, já que na África não havia história. Mas:

Tendo como fundo a voz de Hegel em off, eis Mandela. No fim infinito, não findo, acabado inacabado de sua [sic] autobiografia, as últimas linhas do livro aliam o motivo da reconciliação ao da liberação. Liberação do mestre opressor, duplo genitivo. Ao se liberar do mestre, libera-se a ele mesmo ${ }^{25}$.

Quiçá, o reconhecimento pelo Estado brasileiro de tais crimes implicaria no reconhecimento da restância da Escravidão como racismo institucional. Formulamos a partir da noção de identificação que a confissão da Escravidão, da Shoah e do Apartheid são vias próximas na conjuração do racismo. Medimos que a identificação na memória do sofrimento e na luta pela confissão dos atos praticados agencia a hospitalidade incondicional.

E a memória dos que sofreram e sofrem a tentativa de serem aniquilados pela narrativa nacional brasileira é evocada pela legislação antirracista, não no sentido de abandonar a tradição filosófica ocidental, mas que se faça a reflexão ético-política sobre a herança do Iluminismo e se pense um Iluminismo por-vir capaz de abandonar a lógica binária que ora hostiliza ora hospeda o judeu, o árabe, o negro, etc.

Para insistirmos no apelo por um Iluminismo por-vir precisaremos soçobrar o esquecimento dos rastros das etnias negras que foram aqui escravizadas, evocarmos as memórias dolorosas e o sofrimento, atos e gestos de resistência, individuais e coletivos. Neste sentido não atentamos apenas para o sentido moderno de resistir como sofrer, agüentar e suportar. Num gesto econômico e paleonímico, lembramos que resistir desde o século XVI remete para o ato ou efeito de não ceder, assim como, reagir contra, conflitar, opor-se voluntariamente, insurgir, enfrentar, confrontar, etc. E no caso das singularidades

${ }^{25}$ NASCIMENTO, Jacques Derrida: pensar a desconstrução, p. 71. 
e coletividades negro-brasileiras, sem silenciar a história das pessoas que sofreram, agüentaram e suportaram a escravização, é recuperar toda a memória da luta contra a escravização, assimilação e extermínio.

\section{Qual o lugar da confissão?}

Reconhecemos que a escola é conclamada pela legislação a apresentar-se como o lugar da confissão da Escravidão, da Shoah e do Apartheid. Ao classificar a escola como o local da confissão dos crimes cometidos contra a humanidade a identificamos com a Universidade, apresentada pelo filósofo franco-argelino ${ }^{26}$ como o local da pesquisa e investigação, e da formação dos profissionais que publicarão, confessarão, declararão, arrepender-se-ão, expiarão e solicitarão perdão pelos crimes cometidos contra a espécie humana. Demonstramos que a obra derridiana rasura a distinção entre escola e universidade. Traçamos que a preocupação com o ensino de filosofia permeia a estratégia desconstrutora. Provamos que a legislação antirracista rasura a distinção entre escola e universidade ao conclamar todas as instituições de ensino a desconstruírem-se. Propomos a confissão dos crimes contra a humanidade como estratégia desconstrutora do racismo institucional que atualmente assombra a democracia. Avaliamos que a raça é um espectro, um retornante que para além de assombrar, também apela à hospitalidade in-condicional de todas e todos na sua différance.

O sistema educacional, rememora Derrida, em $O$ monolinguismo do outro ${ }^{27}$, é fundamental na construção da identidade, nacionalidade e cidadania, tanto no continente europeu quanto nos países onde o etnocentrismo tenta impor-se, e a língua, o idioma tem um papel preponderante, outrora como o aspecto identitário que unia cidadãos da metrópole e das colônias e, após os processos emancipatórios, como o aspecto identitário das novas nações, como a restância da dominação europeia que inclui as novas nações no teatro mundial.

E entrar no concerto das nações é imergir-se na crise europeia, pois, a identidade elenca os debates sobre o monoculturalismo e o multiculturalismo, o ipse e o hospes, a hostilidade e a hospitalidade, etc.; além das questões anteriores, a cidadania requere: as questões da abstralidade e da naturalidade, da participação e da exclusão cultural e linguística e histórica, a elegibilidade e a inelegibilidade, a permanência e a precariedade dos marcos jurídicos, concessão ou recusa ou supressão do status de cidadão, quais as condições de supressão e permanência do status de cidadão, etc.

Nos Estados-nação, a língua apresenta-se como uma propriedade natural do nativo europeu (quando se está na Europa) ou do colono europeu (quando se está nas antigas colônias), recusada e estimulada entre os considerados falantes não-naturais, ao mesmo

\footnotetext{
${ }^{26}$ DERRIDA, A universidade sem condição, 2003.

${ }^{27}$ DERRIDA, O monolinguismo do outro: ou a prótese de origem, 2001.
} 
tempo em que o eurocêntrico recusa aos demais a propriedade natural da língua. Ainda que seja a única língua falada pelo considerado falante não-natural, esta é estimulada como o único meio civilizado de comunicação, como o que insere o antes considerado estrangeiro na comunidade nacional sob um status recente e ameaçado e precário.

A língua, então, representa a ameaça de não inclusão e a promessa e esperança de assimilação e participação na coletividade. O endereçamento ao outro ocorre num jogo onde a promessa é ameaçante e a ameaça uma promessa, um jogo desesperante entre a hospitalidade e hostilidade do falante não-natural da língua oficial, sua única língua, e mesmo quando o falante não-natural fale outras línguas, a oficial é a única que o insere na promessa e na ameaça de exclusão de sua participação no teatro da cidadania e da nacionalidade. O equívoco etnocêntrico, diz Derrida, está em não perceber que não há propriedade natural da língua e que toda singularidade humana fala uma língua que não é sua: "Desde então, qualquer pessoa deverá poder declarar sob juramento: eu não tenho senão uma língua inassimilável. A minha língua é-me uma língua inassimilável. A minha língua, a única que me ouço falar e me ouço a falar, é a língua do outro" ${ }^{28}$.

A escola ${ }^{29}$, enquanto o paradigma nacional for o eurocentrismo, entende-se como reprodutora dos valores civilizatórios ocidentais, quando na Europa pretende construir no educando o pertencimento natural aos valores europeus e a missão de preservá-los, e aos considerados estrangeiros ou não-europeus a promessa de assimilação às nacionalidades europeias. Já nos Estados-nação ocidentalizados, opera valorizando o colonizador e o seu papel civilizatório e promete aos demais o ingresso na cidadania, desde que assimilem os valores da Europa e reneguem as heranças não-europeias.

$\mathrm{Na}$ Europa ou fora dela, a promessa de assimilação opera conjuntamente com a ameaça de exclusão dos que não se deixam assimilar. Os programas escolares valorizam a literatura, a história, a geografia, etc, europeias em detrimento de outros conhecimentos, funcionam operando, ao mesmo tempo, a identificação do colonizável com a Europa e a marcação da sua diferença determina qual o papel do colono e do colonizado. Explicitam que a assimilação é impossível quando o lembra de não ser proprietário da língua oficial e que só pode falá-la com sotaque, que o sangue de seus ancestrais não fora derramado no solo europeu, ou quando ressalta que ou não participou da história narrada - nem da europeia e nem do Estado-nação ocidentalizado - ou que quando participou foi num papel subalterno, etc.

\footnotetext{
${ }^{28}$ Idem, p. 39.

${ }^{29}$ Ver também ROSÁRIO, Entrevistas orais/em vídeo via whatsapp: uma proposta didática para a sala de aula de filosofia, 2017.
} 
Quiçá, se lermos e ouvirmos as mulheres negras ${ }^{30}$ se perceberá para além do que foi dito pelo filósofo da desconstrução, que a língua portuguesa funcionou para os ewes, fons, yorubanos, benguelas, etc, como uma ferramenta etnopigmentar de reconstrução de suas vidas assombradas e destruídas pelo sequestro em terras africanas e transporte para as terras americanas, como construção de uma via de solidariedade no sofrimento e fraternidade que soçobrasse as antigas rivalidades étnicas e apontasse rotas de fuga tais como os quilombos ou outras formas de resistência; ou mesmo nos casos em que as diferenças étnicas não foram superadas, a língua funcionou como ferramenta aglutinadora das singularidades de uma mesma etnia para a formação de irmandades religiosas ou outras formas de resistência que serviam como propulsionadoras da solidariedade e fraternidade. A língua, portanto, foi ressignificada e apropriada como arma de sobrevivência e resistência existencial e cultural, individual e coletiva - solicitando o idioma recebido violentamente do colonizador e disseminando-o como o pretugês ${ }^{31}$ do samba, do jongo, da capoeira, do candomblé, da quimbanda, da umbanda, do batuque, dos quilombos, etc., nestes inúmeros acontecimentos de resistência.

\section{Considerações quase-finais: Brasil, hostilidade ou hospitalidade in-condicional}

Apelar, com Derrida ${ }^{32}$, pela democracia por-vir, é reconhecer que nas democracias atuais há um profundo antidemocratismo, como se verifica com o aumento dos crimes de ódio na medida em que o número de estrangeiros num dado Estado-nação aumenta. Sabendo que a democracia por-vir não é um aperfeiçoamento da democracia atual, mas refere-se ao desviar dos in-decidíveis da democracia atual para possibilitar a chegada da hospitalidade.

E neste itinerário de apelo por novas relações e instituições que deputem o perdão, o dom, a confissão, etc, é que se aponta, aqui, a escola como um local privilegiado de chegada da desconstrução. E que a desconstrução do ensino de filosofia chega quando se observa a relação racismo e democracia, quando se reflete sobre as implicações do racismo na escola e a importância da superação do racismo na escola como condição para o exercício da cidadania; quando se percebe que a democracia por-vir é um acontecimento cuja condição de possibilidade é a procura por caminhos que desviem da situação atual de dominação onde o racismo se impõe disfarçadamente sempre que aparece o in-decidível,

\footnotetext{
30 GONZALEZ, Racismo e sexismo na cultura brasileira, 1984; RIBEIRO, O que é lugar de fala?, 2017; SILVA; PEREIRA, O movimento de mulheres negras: escritos sobre os sentidos de democracia e justiça social no Brasil, p. 205-217; ROSARIO, A desconstrução da Universidade e o Movimento de Mulheres Negras, 2018b.

31 Termo empregado por Lélia Gonzales. Ver GONZALES, Racismo e sexismo na cultura brasileira, 1984.

32 DERRIDA, Espectros de Marx: o Estado da divida, o trabalho do luto e a nova Internacional, 1994; DERRIDA, O monolinguismo do outro: ou a prótese de origem, 2001; DERRIDA, Papel-máquina, 2004; DERRIDA, Adeus a Emmanuel Lévinas, 2008.
} 
isto é, sempre que a espectralidade da raça impõe a escolha entre a hostilidade ou a acolhida da diferença e que a escola e a universidade in-condicionais pertencem ao escopo da im-possibilidade e do por-vir, entendida a impossibilidade como a condição de possibilidade de um por-vir onde não há mais lugar para se entender os traços fisionômicos como motivadores da discriminação ou da inferiorização ou da segregação ou do extermínio. Pois:

... é preciso ir (Geh, Vá!) aí aonde não se pode ir. Paixão do lugar, ainda. Eu diria em francês: il y a lieu de (o que quer dizer "é preciso") ir lá aonde é impossível ir. [...] Ir aonde é possível ir não seria um deslocamento ou uma decisão; seria o desenvolvimento irresponsável de um programa. A única decisão possível passa pela loucura do indecidível e impossível ${ }^{33}$.

E como desconstruir esta relação hostil? Como desconstruir os espaços formadores? Como desconstruir o pensamento? A desconstrução já está, já chegou, é o que chega, é o im-possível que chega apelando novas relações na escola. Esta desconstrução da história não objetiva trocar o eurocentrismo marcante por novos centros, antes se legitima no entendimento que "A ausência de centro é aqui a ausência de sujeito e a ausência de autor” ${ }^{34}$, pois os rastros dos sujeitos e autores da história brasileira serão encontrados no "reconhecimento e igual valorização das raízes africanas da nação brasileira, ao lado das indígenas, europeias, asiáticas” ${ }^{35}$.

Pois se espera que o acontecimento chegue, apelando à hospitalidade incondicional de todas e todos na sua différance, e deputa-se com esta pesquisa solicitar a todas e todos os docentes no sentido de que somente a desconstrução de nossa época é capaz encontrar no in-decidível, nas aporias da democracia liberal, no momento de decidir, de solicitar, deputar, apelar e ver chegar o imprevisto, o im-possível, a hospitalidade in-condicional, a democracia por-vir.

\section{Referências}

BRASIL. Diretrizes curriculares nacionais para educação das relações étnico-raciais e para o ensino de história e cultura afro-brasileira e africana. Brasília: SECAD, 2005.

BRASIL. Orientações e ações para educação das relações étnico-raciais. Brasília: SECAD, 2006.

\footnotetext{
${ }^{33}$ DERRIDA, Salvo o nome, p. 42.

${ }^{34}$ DERRIDA, A escritura e a diferença, p. 419.

${ }^{35}$ BRASIL, Diretrizes curriculares nacionais para educação das relações étnico-raciais e para o ensino de história e cultura afro-brasileira e africana, p. 21.
} 
BRASIL. Lei nำ 11.645 de 10 de março de 2008. Altera a Lei nำ 9.394, de 20 de dezembro de 1996, modificada pela Lei no 10.639, de 9 de janeiro de 2003, que estabelece as diretrizes e bases da educação nacional, para incluir no currículo oficial da rede de ensino a obrigatoriedade da temática "História e Cultura Afro-Brasileira e Indígena”. Diário Oficial [da] República Federativa do Brasil, Poder Executivo, Brasília, DF, 11 de mar. 2008.

BRASIL. Plano nacional de implementação das diretrizes curriculares nacionais para a educação das relações étnico-raciais e para o ensino de história e cultura afro-brasileira e africana. Brasília: SEPPIR/MEC/SECAD, 2009.

DERRIDA, Jacques. A escritura e a diferença. Tradução de Maria Beatriz Marques Nizza da Silva, Pedro Leite Lopes e Pérola de Carvalho. São Paulo: Perspectiva, 2011.

DERRIDA, J. Psyché: inventions de l' autre. Paris: Galilée, 1987.

DERRIDA, J. Du droit à la philosophie. Paris: Galilée, 1990.

DERRIDA, J. Margens da filosofia. Tradução de Joaquim Torres Costa e Antonio M. Magalhães. Campinas: Papirus, 1991.

DERRIDA, J. A farmácia de Platão. Tradução Rogério da Costa. São Paulo: Ilumnarias, 1991b.

DERRIDA, J. Espectros de Marx: o Estado da dívida, o trabalho do luto e a nova Internacional. Tradução de Anamaria Skinner. Rio de Janeiro: Relume Dumará, 1994.

DERRIDA, J. O outro cabo. Tradução de Fernanda Bernardo. Coimbra: A Mar Arte, 1995.

DERRIDA, J. Salvo o nome. Tradução Nicia Bonatti. Campinas: Papirus, 1995c.

DERRIDA, J. O monolinguismo do outro: ou a prótese de origem. Tradução de Fernanda Bernardo. Porto: Campo das Letras, 2001.

DERRIDA, J. Posições. Tradução de Tomaz Tadeu da Silva. Belo Horizonte: Autêntica, 2001b.

DERRIDA, J. A universidade sem condição. Tradução de Evandro Nascimento. São Paulo: Estação Liberdade, 2003.

DERRIDA, J. Papel-máquina. Tradução de Evandro Nascimento. São Paulo: Estação Liberdade, 2004.

DERRIDA, J. Une Europe de l' espoir. Le monde diplomatique. Novembre, p. 3, $2004 \mathrm{~b}$. Disponível em https:/www.monde-diplomatique.fr/2004/11/DERRIDA/11677 acesso em 03/02/2019. Uma Europa da esperança. Tradução brasileira de Iraci D. Poleti. Disponível em http://diplo.org.br/2004-11,a1021 acesso em 03/02/2019.

DERRIDA, J. Força de lei: o fundamento místico da autoridade. Tradução de Leyla PerroneMoisés. São Paulo: Martins Fontes, 2007. 
DERRIDA, J. Adeus a Emmanuel Lévinas. Tradução Fábio Landa. São Paulo: Perspectiva, 2008.

DERRIDA, J. Gramatologia. Tradução de Miriam Chnaiderman e Renato Janine Ribeiro. São Paulo: Perspectiva, 2011b.

GONZALEZ, Lélia. Racismo e sexismo na cultura brasileira. Revista Ciências Sociais Hoje. Anpocs, 1984. Disponível em https://goo.gl/VFdjdq acesso em 28/07/2018.

HADDOCK-LOBO, Rafael [et al.]. Heranças de Derrida: da ética a política. Rio de Janeiro: Nau, 2014.

MORAES, Marcelo José Derzi. Desobediência epistemológica: Ubuntu e Teko porã: outros possíveis a partir da desconstrução: In: CORREA, Adriano [et al.] Filosofia francesa contemporânea. São Paulo: Anpof, p. 70-81, 2017. Disponível em http://www.anpof.org/portal/images/filosofia-francesa-contemporanea.pdf acesso em $15 / 12 / 2018$.

MORAES, M. J. D. Desconstruindo o epistemicídio a partir de Jacques Derrida. Análogos. Rio de Janeiro, edição especial, p. 16-26, 2017b. Disponível em https://www.maxwell.vrac.puc-rio.br/30440/30440.PDF acesso em 22/01/ 2019.

MORAES, M. J. D. Democracias espectrais: uma abordagem a partir de Jacques Derrida. Tese (Doutorado em Filosofia. Instituto de Filosofia e Ciências Humanas. Universidade do Estado do Rio de Janeiro, Rio de Janeiro, 2018.

MORAES, Marcelo José Derzi; SANTOS, Adriano Negris. O pensamento do ético em Jacques Derrida: uma questão de hospitalidade. Cadernos de ética e filosofia política (USP), v. 30, p. 20-35, 2017. Disponível em file:///C:/Users/win8/Downloads/138727Texto\%20do\%20artigo-269452-1-10-20171002.pdf acesso em 03/11/2018.

NASCIMENTO, Evando. Jacques Derrida: pensar a desconstrução. São Paulo: Estação Liberdade, 2005.

RIBEIRO, Djamila. O que é lugar de fala? Belo Horizonte: Letramento/Justificando, 2017.

ROSARIO, Fábio Borges. A questão do ensino de filosofia na educação básica e a implementação das leis 10.639/03 e 11.645/08: análise dos documentos normativos e curriculares nacionais para o ensino de filosofia e dos livros didáticos de filosofia aprovados pelo Programa Nacional do Livro Didático (PNLD) do Ministério da Educação (MEC). Trabalho de Conclusão de Curso (Especialização em Especialista em Ensino de Histórias e Culturas Africanas e Afro-brasileira). São Gonçalo, Instituto Federal de Educação, Ciência e Tecnologia do Rio de Janeiro, 2013.

ROSÁRIO, F. B. Entrevistas orais/em vídeo via whatsapp: uma proposta didática para a sala de aula de filosofia. Maçã com canela: produtos educacionais e outros textos. In: 
CASTANHEIRA, [et al.] (Orgs.). Chás para a filosofia, v. 5. Rio de Janeiro: Publit, p. 104-113, 2017.

ROSÁRIO, F. B. O conceito de antirracismo e a confissão de crimes contra a humanidade: In: CORREA, Adriano [et al.] (Orgs.). Filosofia francesa contemporânea. São Paulo: Anpof, p. 20-38, 2017b. Disponível em http://www.anpof.org/portal/images/filosofia-francesacontemporanea.pdf acesso em 15/12/2018.

ROSÁRIO, F. B. A desconstrução do ensino de filosofia e a legislação antirracista. Dissertação (Mestrado em Filosofia e Ensino). Rio de Janeiro, Centro Federal de Educação Tecnológica Celso Suckow da Fonseca, 2018.

ROSÁRIO, F. B. A desconstrução da Universidade e o Movimento de Mulheres Negras. Café: formação e autoformação em filosofia e outros cafés. In: PINTO, Felipe Gonçalves [et al] (Orgs.). Chás para a Filosofia. v. 6, Rio de Janeiro: Publit, p. 241-255, 2018b.

SILVA, Joselina da; PEREIRA, Amauri Mendes (Orgs.). O movimento de mulheres negras: escritos sobre os sentidos de democracia e justiça social no Brasil. Belo Horizonte: Nandyala, 2014.

SOLIS, Dirce Eleonora Nigro. Desconstrução em arquitetura e hospitalidade: uma abordagem a partir de Derrida. Revista de filosofia SEAF. Ano 4, n 4, p.109-133, 2004.

SOLIS, D. E. N. Jacques Derrida e a ética da hospitalidade. In: Revista de filosofia SEAF. Ano 5, nํㅜ, p. 64-78, 2005.

SOLIS, D. E. N. Desconstrução e arquitetura: uma abordagem a partir de Jacques Derrida. Rio de Janeiro: Uapê/Seaf, 2009.

SOLIS, D. E. N. Retórica e desconstrução segundo Jacques Derrida. Revista de filosofia SEAF. Ano 11, n 11, p. 43-71, 2012.

SOLIS, D. E. N.; MORAES, Marcelo (Orgs.). Políticas do lugar. Porto Alegre: UFRGS, 2016. 